\title{
SEOM Guidelines 2013: a response to the needs of Spanish oncologists
}

\author{
J. J. Cruz-Hernández • C. A. Rodríguez
}

Received: 19 July 2013/Accepted: 28 July 2013/Published online: 8 August 2013

(c) Federación de Sociedades Españolas de Oncología (FESEO) 2013

In this issue of Clinical and Translational Oncology, the Spanish Society of Clinical Oncology (SEOM) publishes the fourth part of the SEOM's Clinical Practice Guidelines. First guidelines were published in 2010, and 3 years later the scientific committee and the executive board of the Spanish Society of Clinical Oncology have found necessary to publish an updated edition of some of the early guides reported, dedicated to different tumors in which the continuous changes that have taken place in the medical treatment of cancer made necessary a deep review [1-8]. Similarly, the guide for the treatment of emesis induced by chemotherapy has been updated [9], and the guide for the treatment of osteosarcoma has also been incorporated [10].

In our opinion, there is no doubt of the need of editing local guides about the medical treatment of cancer. Maybe it could be considered that there are already published many other similar guides, edited by scientific societies or committees of experts. This would make SEOM guidelines unnecessary. Nothing further from the truth. It is well known that the quality of patient care often varies depending on numerous factors, such as health care setting, geographic area, access to new drugs, insurance coverage, and treatment protocols [11]. These differences in health care are well established, and frequently they can lead to different services provided to the patients depending on the location. Thus, some authors consider guidelines, pathways and protocols as useful tools to reduce disparities [11]. At present, the situation of economic crisis in Spain has led, inevitably, to diverse

J. J. Cruz-Hernández · C. A. Rodríguez ( $₫)$

Spanish Society of Medical Oncology, Servicio de Oncología

Médica, Hospital Clínico Universitario, Po San Vicente, 58-182,

37007 Salamanca, Spain

e-mail: crodriguez@oncologiasalamanca.org restrictions in the use of anticancer drugs, depending on the region considered or the healthcare provider. This fact has been taken into account by the SEOM, which has positioned unequivocally as a guarantee of equity of access to treatments for all patients. In addition, Spanish oncologists, demand evidence-based tools developed from a close perspective, that they can use as a reference, with the aim of claiming the best treatments to health authorities. Probably the use of clinical guidelines can reduce costs, and specially contribute to avoid inappropriate variability in the medical treatment of cancer.

The SEOM board will make in the future issues a new special effort for review and actualize the rest of the previous published guidelines and for publishing new ones with information for the rest of solid tumors as well as for supportive care and symptom control, contributing to the best care of Spanish cancer patients.

Conflict of interest The authors declare that they have no conflict of interest.

\section{References}

1. Camps C, Felip E, García-Campelo R, Trigo JM, Garrido P. SEOM Clinical Guidelines for the treatment of non-small cell lung cancer. Clin Transl Oncol. 2013. doi:10.1007/s12094-013-1085-2.

2. Dómine M, Morán T, Artal A, Remon J, Lianes P. SEOM Clinical Guidelines for the treatment of small-cell lung cancer. Clin Transl Oncol. 2013. doi:10. 1007/s12094-013-1086-1.

3. Maurel J, Grávalos C, Rivera F, Vera R, González E. SEOM Clinical Guidelines for the adjuvant treatment of colorectal cancer. Clin Transl Oncol. 2013. doi:10. 1007/s12094-013-1083-4.

4. Casado E, Feliu J, Gomez MA, Sanchez-Gastaldo A, García-Carbonero R. SEOM Clinical Guidelines for the treatment of advanced colorectal cancer. Clin Transl Oncol. 2013. doi:10.1007/s12094-013-1082-5.

5. Llombart A, De la Haba J, Ruiz A, Álvarez I, Cortés J. SEOM Clinical Guidelines for the management of metastatic breast cancer. Clin Transl Oncol 2013. doi:10.1007/s12094-013-1095-0.

6. Del Barco S, Ciruelos E, Tusquets I, Ruiz M, Barnadas A. SEOM Clinical Guidelines for the systemic treatment of early breast cancer. Clin Transl Oncol. 2013. doi:10.1007/s12094-013-1084-3. 
7. Mesía R, Pastor M, Grau JJ, Del Barco E. SEOM Clinical Guidelines for the treatment of head and neck cancer. Clin Transl Oncol. 2013. doi:10.1007/ s12094-013-1096-z.

8. Mesía R, Pastor M, Grau JJ, Del Barco E. SEOM Clinical Guidelines for the treatment of nasopharyngeal carcinoma. Clin Transl Oncol. 2013. doi:10.1007/ s12094-013-1094-1.

9. García-Gómez J, Pérez ME, Alonso M, Escobar Y, García Mata J. SEOM Clinical Guidelines to antiemetic prophylaxis in cancer patients treated with chemotherapy. Clin Transl Oncol. 2013. doi:10.1007/s12094-013-1093-2.
10. Redondo A, Cruz J, Lopez A, Barón FJ. SEOM Clinical Guidelines for the treatment of osteosarcoma in adults. Clin Transl Oncol. 2013. doi:10.1007/ s12094-013-1087-0.

11. DeMartino JK, Larsen JK. Equity in cancer care: pathways, protocols, and guidelines. J Natl Compr Canc Netw. 2012;10(Suppl 1):S1-9. 